\title{
STUDI ETNOMATEMATIKA : KAIN BERBAHAN DASAR HALAL DITINJAU DARI MOTIF SADULUR BATIK LEBAK PROVINSI BANTEN
}

\author{
Andri Imam Subekhi ${ }^{1}$, Swastika Oktavia ${ }^{2}$ \\ Pendidikan Guru Sekolah Dasar, STKIP Babunnajah Pandeglang, Indonesia ${ }^{1}$ \\ Program Studi Biologi', Universitas Mathla'ul Anwar Banten, Pandeglang, Indonesia ${ }^{2}$ \\ Korespondensi Author: andriimamsubekhi@gmail.com
}

\begin{abstract}
Ethnomatematics is mathematics that is contained in culture. The purpose of this research is to examine the material of the sadulur batik lebak banten motif through aspects of halal products. The research method used is a qualitative method with an ethnographic approach. The data collection techniques used are literature study, interviews and documentation. The data analysis techniques used were data reduction, data presentation, and conclusion drawing. Data validity checks were carried out by extending observations, increasing persistence, using reference materials. The result of this research is that in the batik sadulur motif of lebak banten, there is a halal aspect of the material used in the form of batik cloth, the equipment used such as cloth, chanting and coloring.
\end{abstract}

Keywords: Ethnomatematics; Batik Sadulur; Motifs Lebak Offer; Made From Halal

\begin{abstract}
Abstrak: Etnomatematika merupakan matematika yang terdapat dalam budaya. Tujuan dari penelitian ini untuk meninjau bahan kain motif sadulur batik lebak banten melalui aspek produk halal. Metode penelitian yang digunakan adalah metode kualitatif dengan pendekatan etnografi. Adapun teknik pengumpulan data yang digunakan yaitu studi pustaka, wawancara dan dokumentasi. Teknik analisis data yang digunakan yaitu reduksi data, penyajian data, dan penarikan kesimpulan. Pengecekan keabsahan data dilakukan dengan perpanjangan pengamatan, meningkatkan ketekunan, menggunakan bahan referensi. Hasil dari penelitian ini adalah pada motif sadulur Batik lebak banten terdapat aspek halal dari bahan yang digunakan berupa kain batik, peralatan yang digunakan seperti kain, chanting dan pewarnaan.
\end{abstract}

Kata Kunci: Etnomatematika; Motif Sadulur; Batik Lebak Banten; Berbahan Halal.

\section{PENDAHULUAN}

Matematika merupakan ilmu universal yang mendasari perkembangan teknologi modern, mempunyai peran penting dalam berbagai disiplin dan memajukan daya pikir manusia. Perkembangan pesat di bidang teknologi informasi dan komunikasi dewasa ini dilandasi oleh perkembangan matematika di bidang teori bilangan, aljabar, analisis, teori peluang dan matematika diskrit. Untuk menguasai dan mencipta teknologi di masa depan diperlukan penguasaan matematika yang kuat sejak dini, (Lestari, 2015). Oleh karena itu manusia perlu melakukan penghitungan dan pengukuran untuk menggambar desain rumah, gedung dan stadion. Dan memperkirakan jumlah bahan bangunan yang diperlukan untuk membuat 
bangunan tersebut. Selain itu, perkembangan teknologi modern yang terjadi saat ini juga tidak luput dari peran matematika.

Menurut D’Ambrosio (Ridwan,2018) pada masa sebelum sekolah dan di luar sekolah di dunia ini hampir semua anak telah menjadi "matherate" artinya, mereka mampu mengembangkan kemampuan untuk menghitung, menggunakan bilangan, dan menggunakan beberapa pola inferensi. Tetapi, seorang individu yang dengan sempurna telah mampu menggunakan bilangan, bentuk geometris, operasi, dan gagasan, ketika di sekolah dihadapkan pada pendekatan yang sama sekali baru dan formal mengenai fakta-fakta. Sebagai akibatnya, terbentuklah penyumbatan psikologis yang tumbuh sebagai penghalang antara perbedaan model-model numerik yang dipelajari di sekolah dengan pemikiran geometris yang sudah dipelajarinya dari kehidupan nyata sebelum atau di luar sekolah, sehingga tahap awal pendidikan matematika memberikan pengaruh pada anak rasa kegagalan, ketergantungan, bahkan kehilangan kemampuan matematis yang telah dimiliki pada masa pra sekolah. Hal tersebut menunjukkan bahwa pembelajaran matematika di sekolah terlepas dari kehidupan nyata yang kaya akan budaya dan peradaban.

Matematika dianggap sebagai sesuatu yang netral dan terbebas dari budaya (culturralyfree). Seperti yang diungkapkan oleh Rosa dan Orey (Prabawati, 2016), bahwa "mathematics always taught in scholl as a culturaly free subject that involved learning supposedly universally accepted facts, concept and content". Matematika dipelajari di sekolah sebagai mata pelajaran yang tidak terkait dengan budaya yang secara umum pembelajarannya meliputi fakta-fakta, konsep, dan materi. Matematika juga dianggap sebagai ilmu pengetahuan yang sempurna dengan kebenaran yang objektif dan dirasakan jauh dari realitas kehidupan sehari-hari. Hal ini sejalan dengan aktivitas perdagangan atau jual beli barang yang dilakukan oleh manusia memerlukan matematika untuk menghitung besar keuntungan atau kerugian yang dialami.

Turmudi (Prabawati, 2016) menyatakan bahwa matematika berurusan dengan gagasan, matematika bukan tanda-tanda sebagai akibat dari coretan pensil, bahkan kumpulan bendabenda fisik berupa segitiga, namun berupa gagasan yang direpresentasikan oleh benda-benda fisik. Sehingga menurut Turmudi terdapat tiga sifat utama dari matematika. Pertama, matematika sebagai objek yang ditemukan dan diciptakan manusia. Kedua, matematika itu diciptakan bukan jatuh dengan sendirinya, namun muncul dari aktivitas yang objeknya telah tersedia, serta dari keperluan sains dan kehidupan keseharian. Ketiga, sekali diciptakan objek matematika memiliki sifat-sifat yang ditentukan secara baik. Matematika juga dianggap sebagai ilmu pengetahuan yang sempurna dengan kebenaran yang objektif dan dirasakan jauh dari realitas kehidupan sehari-hari. 
Menurut Clement (Prabawati, 2016), dari hasil pertemuan International Community of Mathematics Education menyebutkan bahwa permasalahan yang terkait dengan budaya mau tidak mau akan mengelilingi proses pembelajaran matematika, bahkan semua bentuk-bentuk matematika. Hal ini berkesinambungan dengan pembelajaran matematika sekolah saat ini, banyak mengadopsi dari pembelajaran matematika negara luar yang dianggap lebih maju. Indonesia dengan keragaman budayanya sudah seharusnya memasukkan nilai-nilai budaya setempat ke dalam pembelajaran matematika, agar matematika tidak dianggap sebagai ilmu pengetahuan yang jauh dari realitas kehidupan.

Salah satu tujuan dalam mempelajari matematika adalah dengan menguasai dan memahami proses berpikir matematika itu sendiri. Hal ini dipertegas oleh pendapat Suriasumantri, J. S, (Nurroh, 2017) yang menyatakan bahwa berpikir adalah suatu kegiatan untuk menemukan pengetahuan yang benar. Bagaimana mungkin seorang siswa dapat mengaplikasikan matematika yang sistematis dan logis dalam kehidupan nyata jika cara berpikirnya rendah. Di sini terlihat jelas bahwa banyak konsep-konsep matematika diperlukan oleh ilmu lain dan matematika harus dapat bermanfaat untuk kehidupan seharihari di masyarakat.

Matematika merupakan suatu kegiatan sosial dan aktivitas manusia (Schoenfeld; 1992, Gravemeijer; 1997). Matematika berupaya memahami pola yang terjalin, baik dalam lingkungan sekitar yang merupakan dunia nyata, maupun dalam alam pikiran kita. Meskipun bahasa matematika berlandaskan pada suatu aksioma-aksioma yang ketat, akan tetapi karena matematika juga merupakan aktivitas sosial maka menurut (Schoenfeld; 1992). Transformasi ini menuntut adanya perubahan pada muatan kurikulum dan strategi pembelajaran yang berfokus pada upaya; menemukan penyelesaian, bukan hanya menghafal prosedur; menjelajahi pola, tidak hanya menghafal rumus, dan merumuskan tebakan, tidak hanya mengerjakan latihan.Sejalan dengan pendapat tersebut, bahwa hakekat pendidikan matematika mempunyai dua arah pengembangan, yaitu pengembangan untuk kebutuhan masa kini dan masa akan datang.

Sejalan pendapat tersebut siswa yang paham akan suatu konsep matematis umumya akan memiliki pola pikir yang jauh lebih baik ketimbang siswa yang tidak paham suatu konsep, demikian pula siswa yang memiliki proses berpikir matematika yang baik, maka konsep yang dimilikipun juga diasumsikan baik.

Hal ini juga berlaku umum bagi suatu individu maupun kelompok sosial bahwa kekurangpahaman akan suatu konsep menyebabkan proses berpikirnya juga menyesuaikan dengan apa yang dipahaminya. Oleh karena itu, lingkungan merupakan salah satu faktor utama dalam membentuk suatu pola dan pemahaman akan suatu hal sehingga proses 
berpikirnya juga akan mengikuti. Salah satu model pembelajaran sekaligus strategi yang baik dalam memahami karakter suatu individu ataupun masyarakat belajar adalah dengan mempelajari etnomatematika.

Etnomatematika merupakan salah satu kajian yang baru dan koheren. Sebagai salah satu kajian yang baru, etnomatematika berperan penting dalam mengeksplorasi nilai-nilai luhur pada kebudayaan masyarakat. Sependapat dengan D'Ambrosio mengungkapkan etnomatematika merupakan matematika yang dipraktikkan oleh kelompok budaya seperti masyarakat adat, kelompok buruh, masyarakat perkotaan dan pedesaan, anak-anak dari kelompok usia tertentu, dan lainnya D'Ambrosio (Maharani, 2018). Hal tersebut menunjukan bahwa pembelajaran matematika di sekolah terlepas dari kehidupan nyata yang kaya akan budaya dan peradaban.

Oleh karena itu etnomatematika merupakan matematika yang tumbuh dan berkembang dalam kebudayaan tertentu. Sedangkan budaya merupakan suatu kebiasaan yang mengandung unsur-unsur nilai penting dan fundamental yang diwariskan dari generasi ke generasi. Dalam etnomatematika kebiasaan-kebiasaan yang dilakukan tidak lepas dari penerapan konsep matematika, sehingga memberikan hasil unik dan beragam. (Maharani, 2018). Secara singkat, pengertian dari etnomatematika adalah bentuk matematika yang dipengaruhi oleh budaya.

Barton (Ridwan,2018) berpendapat bahwa etnomatematika dapat dipandang sebagai suatu ranah kajian penelitian yang meneliti cara sekelompok orang pada budaya tertentu dalam memahami, mengekspresikan, dan menggunakan konsep-konsep serta praktik-praktik kebudayaannya yang digambarkan oleh peneliti sebagai sesuatu yang matematis. Oleh karena itu budaya dapat dijadikan sebagai sumber belajar matematika.

Sayangnya, fenomena yang dirasakan sekarang adalah masyarakat masih memandang matematika sebagai suatu ilmu pengetahuan yang sempurna dan kebenarannya yang objektif (body of infallible and objective truth), jauh dari urusan kehidupan manusia, Turmudi (Sholeha, 2016). Timbulnya paradigma absolut terhadap matematika telah dirasakan sejak ribuan tahun yang lalu akibat dari kolonialisme terhadap matematika dan pendidikan matematika.

Padahal sangat mungkin jika seseorang dapat mendewakan matematika sekaligus dapat memfokuskan diri terhadap humaniora sastra jika semua kalangan telah memandang bahwa matematika memiliki pengaruh yang timbal balik dengan budaya Ulum (Sholeha, 2016). Selain itu dalam pandangan yang lebih luas terhadap matematika ditinjau dari sejarah lahirnya matematika. 


\section{METODE}

Penelitian ini dilakukan mulai September 2020 hingga Desember 2020. Penelitian ini dilakukan di Kampung Pancur, Desa Bojong leles, Kecamatan Cibadak, Kabupaten Lebak, Banten. Lokasi ini dipilih dikarenakan Desa bojong leles merupakan tempat terciptanya Batik lebak banten. Informan dalam penelitian ini yaitu seorang pembatik di Desa bojong leles, lebak banten dan seorang pemilik Batik lebak gerai chanting pradana. Jenis penelitian ini merupakan penelitian kualitatif dengan pendekatan etnografi. Pendekatan etnografi digunakan untuk mendapatkan deskripsi tentang budaya yang terdapat pada Batik lebak banten.

Sedangkan kualitatif digunakan untuk mendeskripsikan dan menganalisis informasi secara keseluruhan. Dimana penyajian data pada penelitian kualitatif berbentuk deskriptif atau kata-kata. Teknik pengumpulan data yang dilakukan pada penelitian ini yaitu studi pustaka, wawancara dan dokumentasi. Instrumen utama dalam penelitian ini yaitu peneliti sendiri, sedangkan instrumen pendukung dalam penelitian ini yaitu pedoman wawancara. Teknik analisis data yang digunakan dalam penelitian ini yaitu reduksi data, penyajian data, kesimpulan. Pengecekan keabsahan data yang dilakukan pada penelitian ini yaitu perpanjangan pengamatan, meningkatkan ketekunan, menggunakan bahan referensi.

\section{HASIL DAN PEMBAHASAN}

Penelitian ini mewancarai beberapa narasumber yang dianggap akan membantu dalam proses pengumpulan data penelitian pada subbab ini diuraikan informasi tentang narasumber dalam penelitian ini. Berikut adalah identitas dari narasumber tersebut:

a. Narasumber ke 1

Narasumber pertama adalah anak ketiga dari empat bersaudara dan sekaligus anak pemilik usaha batik lebak Chanting Pradana. Wawancara dengan narasumber pertama dilaksanakan pada 20 September 2020. Pelaksanaan wawancara bertempat di kediaman responden I dan berlangsung pada pukul 12.30 WIB sampai dengan pukul 13.30 WIB. Kegiatan pengambilan data ini menggunakan instrument pedoman wawancara sebagai petunjuk hal apa saja yang harus ditanyakan kepada responden, namun ada juga yang keluar dari daftar pertanyaan pada pedoman tersebut untuk menggali lebih mendalam tentang batik lebak. Dokumentasi dilakukan dengan pengambilan video dan foto dengan seijin responden.

$\begin{array}{ll}\text { Nama } & \text { : Iis Haryati } \\ \text { Tempat Lahir } & \text { : Lebak } \\ \text { Alamat } & \text { : Kampung pancur, Desa Bojongleles, Kec. Cibadak-Lebak } \\ \text { Profesi saat ini } & : \text { Penjaga Toko Gerai Chanting Pradana } \\ \text { Usia } & : \text { 24 Tahun }\end{array}$


1) Informan

Pertanyaan dan jawaban S1 mengenai informasi informan

P1001 : Namanya siapa?

S1001: Iis Haryati

P1002: Berapa usianya?

S1002: 24 Tahun

P1003: Sehari-hari aktifitasnya apa saja?

S1003: Menjaga Galeri Toko Chanting Pradana Lebak

P1004: Apa saja fungsi batik lebak itu sendiri?

S1004: Melestarikan kebudayaan lokal

P1005: Apa yang membedakan batik lebak dengan batik lainnya?

S1005: Batik lebak memiliki unsur kebudayaan lebak seperti makanan khasnya, tempat wisata, dan lain-lain.

Dari hasil wawancara dengan $\mathrm{S} 1$ diperoleh informasi bahwa pemberi informan memenuhi kriteria dalam pengambilan data dan sebagai narasumber. Informan merupakan anak dari pengelola gerai batik chanting pradana lebak banten.

2) Proses pembuatan batik lebak

Pertanyaan dan jawaban S1 mengenai proses pembuatan batik lebak

P1006: Apa saja hal yang perlu dipersiapkan sebelum membuat batik lebak?

S1006: Bahan-bahan yang mau digunakan membatik, sumber daya manusia yang memadai

P1007: Apa saja peralatan yang digunakan dalam membuat batik lebak?

S1007: Chanting, cap, drum, bak, kayu bakar, meja, nampan buat lilin.

P1008: Apa kendala yang dialami dalam membuat batik lebak?

S1008: Musim hujan jadi pengeringan lama

P1009: Berapa lama waktu yang diperlukan untuk membuat batik lebak tersebut?

S1009: Prosesnya cepat, jika pesanannya sedikit perlu waktu 1-2 hari, tetapi jika

pesanannya banyak membutuhkan waktu 3 hari sampai dengan 1 minggu

Dari hasil wawancara dengan S1 diperoleh informasi bahwa dalam sehari sampai dua hari dengan teknik cap menghasilkan beberapa potong saja tergantung pesanan. Jika pesanannya banyak memerlukan waktu tiga sampai tujuh hari. Waktu yang dibutuhkan untuk penyelesaian suatu motif batik lebak relatif sama, sehingga tidak begitu ada perbedaan waktu dalam penyelesaian batik dengan moif yang berbeda-beda.

3) Ide matematis batik lebak

Pertanyaan dan jawaban S1 mengenai ide matematis batik lebak

P1010: Apakah bahan kainnya dibuat sendiri atau membeli sudah ada?

S1010: bahan kainnya dari jawa timur, kainnya polos putih

P1011: Jika dibuat sendiri bagaimana pewarnaan pada kain tersebut? 
S1011: untuk pewarnaan kain batik sendiri dibuat oleh pembatik kami P1012: Pada batik lebak terdapat motif apa saja?

S1012: Motif seren taun, motif sawarna, motif gula sakojor, motif pare sapocong, motif kahirupan baduy, motif leuit sijimat, motif rangkasbitung, motif caruluk saruntuy, motif lebak bertauhid, motif angklung buhun, motif kalimaya, motif sadulur, motif curug muding, motif layur, motif gacong dan motif angklung.

P1013: Bagaimana cara membuat motif batik lebak tersebut?

S1013: Menggunakan chanting cap sesuai pesanan motif batik yang dipesan

P1014: Apakah dalam pembuatan motif batik lebak tersebut mengikuti apa yang diajarkan atau berkreasi sendiri?

S1014: yang sudah diajarkan ada bisa atau kita berkreasi sendiri, misalkan motif layur, motif gacong dan motif angklung hasil dari kreasi sendiri.

Berdasarkan wawancara dengan S1 ide matematis batik lebak bahan kainnya dari jawa timur, kainnya polos putih. Beberapa motif batik lebak diantaranya Motif seren taun, motif sawarna, motif gula sakojor, motif pare sapocong, motif kahirupan baduy, motif leuit sijimat, motif rangkasbitung, motif caruluk saruntuy, motif lebak bertauhid, motif angklung buhun, motif kalimaya, motif sadulur, motif curug muding, motif layur, motif gacong dan motif angklung. yang sudah diajarkan ada bisa atau kita berkreasi sendiri, misalkan motif layur, motif gacong dan motif angklung hasil dari kreasi sendiri.

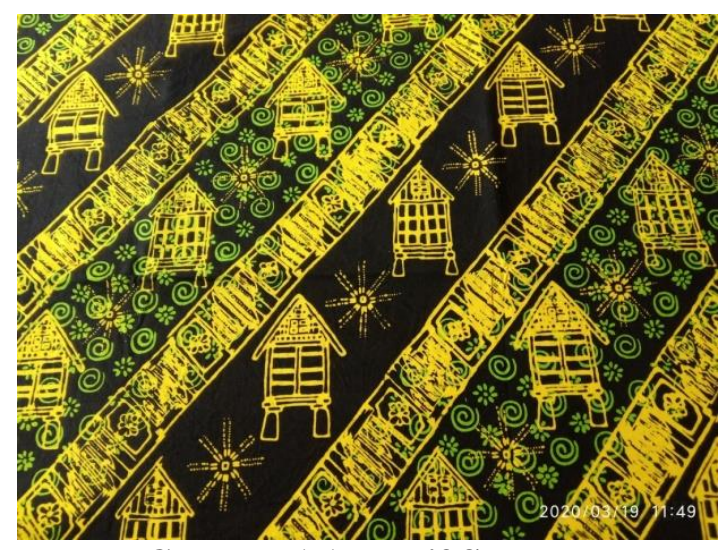

Gambar 1.1. Motif Sadulur

(Dokumentasi pribadi)

Kahirupan baduy adalah aktivitas keseharian masyarakat suku baduy. Ornamen utama batik ini terdiri dari rumah panggung sebagai tempat tinggal suku baduy, dengan mata pencaharian utamanya berladang (huma) yang dilambangkan dengan adanya ornament lantaian (tempat jemuran padi), dan leuit (tempat penyimpanan padi) serta aktivitasnya. Motif batik ini mempunyai filosofi melambangkan kehidupan bersahaja dengan kelestarian alam yang kental dengan budaya, selanjutnya motif batik sadulur dilambangkan oleh dua 
jenis leuit (lumbung padi) yang berada dikesepuhan lebak selatan dan jenis leuit suku baduy. Dari dua jenis leuit yang berbeda tapi mempunyai fungsi dan manfaat sama yaitu sebagai tempat penyimpanan padi. Ornamen batik sadulur terdiri dari dua buah leuit (lumbung padi), leuit kesepuhan lebak selatan, dan leuit suku baduy dengan ornamen tambahan motif tenun baduy dan angklung. Motif batik ini mempunyai filosofi melambangkan kekeluargaan, kesejahteraan dan kebersamaan.

Konsep untuk mencari luas motif dari motif kahuripan baduy dan motif sadulur yang berbentuk segitiga sama kaki dalam matematika adalah

$$
\text { Luas segitiga }=\frac{1}{2} \text { xalasxting } i
$$

Sedangkan untuk mencari keliling motif kahuripan baduy yang berbentuk segitiga sama kaki dalam matematika adalah

\section{Keliling segitiga $=$ jumlah dari tiga sisi segitiga}

Sehingga dalam hal ini luas dan keliling motif kahuripan baduy yang berbentuk segitiga sama kaki, maka keliling satu segitiga kahuripan baduy adalah

Keliling segitiga $=$ jumlah dari tiga sisi segitiga

Keliling segitiga $=$ jumlah dari tiga sisi segitiga

Keliling segitiga $=\mathrm{AB}+\mathrm{BC}+\mathrm{AC}$

Dalam motif Serujit pada Batik Indramayu terdapat unsur matematik diantaranya bentuk yang dimaksud kotak-kotak jaring membentuk persegi, motif sampingnya membentuk segitiga (Sudirman et al., 2018). Pola segitiga terdapat juga pada budaya lain yaitu budaya Jawa. Pada budaya Jawa terdapat rumah Joglo dimana pada bagian atapnya terdapat pola segitiga yang khas (Pramudita dan Rosnawati, 2019).

memuat Graf Star dari motif batik lebak terdapat di motif sadulur.

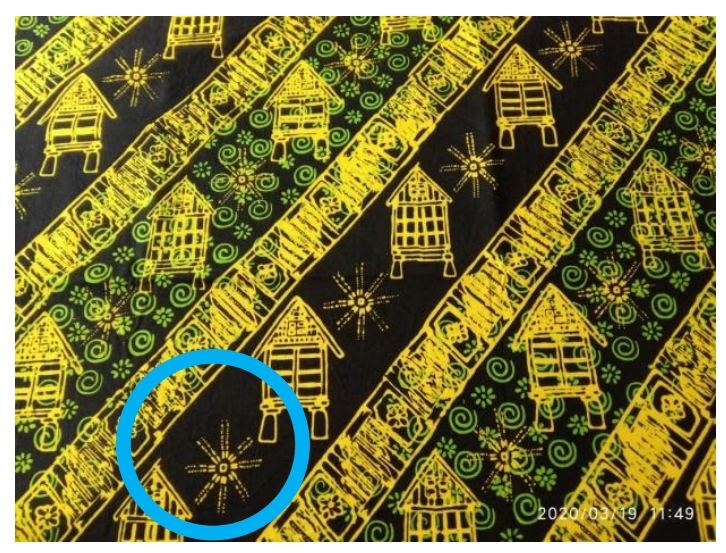

Gambar 1.2. Motif Sadulur

(Dokumentasi pribadi) 


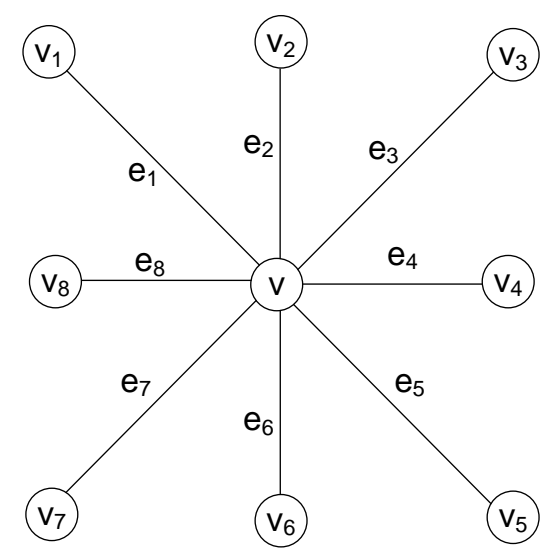

Gambar 1.3. Graf Star $K_{1,8}$

Graf pada Gambar 4.33 merupakan graf dengan himpunan titik $V(G)=\left\{v_{1}, v_{2}, v_{3}, v_{4}, v_{5}, v_{6}, v_{7}, v_{8}\right\}$ dan himpunan sisi $E(G)=\left\{e_{1}, e_{2}, e_{3}, e_{4}, e_{5}, e_{6}, e_{7}, e_{8}\right\}$ dimana $e_{1}=\left(v, v_{1}\right), \quad e_{2}=\left(v, v_{2}\right), \quad e_{3}=\left(v, v_{3}\right), \quad e_{4}=\left(v, v_{4}\right), e_{5}=\left(v, v_{5}\right)$, $e_{6}=\left(v, v_{6}\right), e_{7}=\left(v, v_{7}\right), e_{8}=\left(v, v_{8}\right)$.

Pola graf star juga terdapat pada batik motif Ceplok dari daerah Jawa (Pramudita dan Rosnawati, 2019). Selain itu pada kajian etnomatematika wilayah Asia lain adalah pada pola bordir Bedouin yang berasal dari busana tradisional perempuan di daerah Israel bagian selatan yang memiliki pola graf star. Pola ini terdapat di bagian leher hingga dada yang menyerupai bentuk bunga (Fouze dan Amit, 2019).

\section{KESIMPULAN}

Kesimpulan dari temuan-temuan dalam penelitian yang menjawab dari permasalahan penelitian ini dan saran atau rekomendasi tindak lanjut bagi penelitian berikutnya. Penelitian etnomatematika ini mengungkap berbahan halal ditinjau dari kain motif sadulur batik lebak provinsi banten.

Kesimpulan dari penelitian ini adalah: Motif batik lebak memuat aspek geometris. Pertama memuat aspek geometris persegi panjang diantaranya motif pare sapocong, motif sadulur, dan motif lebak bertauhid.. Kedua memuat aspek geometris segitiga diantaranya motif kahirupan baduy, dan motif sadulur. Ketiga memuat graf star diantaranya motif caruluk saruntuy dan motif sadulur.

Ide-ide matematis geometri yang termuat dalam aktivitas membatik motif batik lebak adalah simetri pada titik, simetri pada garis, persegi panjang, segitiga, dan graf star. Hal tersebut menandakan bahwa aktivitas membatik masyarakat lebak mempertahankan kearifan lokalnya di mana secara informal sudah menerapkan konsep-konsep geometris dalam kehidupan sehari-hari terutama pada motif batik lebak banten. 


\section{DAFTAR PUSTAKA}

Arisetyawan, A., D. Suryadi, T. Herman, \& C. Rahmat. (2014). Study of Ethnomathematics: A lesson from the Baduy Culture. International Journal of Education and Research, 2 (10) : 681-688.

Ascher, M., \& R. Ascher. (1986). Ithaca College. Science History Publications Ltd.

Afifah, D. S. N., I. M. Putri, \& T. Listiawan. (2019). Eksplorasi etnomatematika pada batik gajah mada motif sekar jagad tulungagung, 14 (1) : 101-112.

Borba, M. C. (1992). Teaching Mathematics: Ethnomathematics, the Voice of Sociocultural Groups. The Clearing House, 65 (3) : 134-135.

Brandt, A., \& Chernoff, E. J. (2014). The Importance of Ethnomathematics in the Math Class, (71), 31-36.

Babujee, J. B. \& S. Loganathan. On Signed Product Cordial Labeling. Applied Mathematics, 2 (12) : 1525-1530.

Chrissanti, M. I. (2018). Etnomatematika sebagai salah satu upaya penguatan kearifan lokal dalam pembelajaran matematika. Math Didactic : Jurnal Pendidikan Matematika, 4 (XXXII) : 243-252.

Flick, U. (2014). The Sage Handbook Of Qualitative Data Analysis. SAGE Publications Ltd., London.

Funan, F. X. \& O. Mamoh. (2019). Eksplorasi Etnomatematika UEM LE'U Insana Dalam Kaitannya Dengan Konsep Geometri. Range : Jurnal Pendidikan Matematika, 1 (1) : 63-75.

Fouze, A. Q., \& M. Amit. (2019). Ethnomathematics and Geometrical Shapes in Bedouin Women's Traditional Dress. Creative Education, 10 :1539-1560.

Gunawan, F. I. (2019). Kajian Etnomatematika Serta Analisis Aktivitas Fundamental Matematis Menurut Bishop Pada Industri Kain Cual Bangka Belitung. Tesis. Universitas Sanata Dharma, Yogyakarta.

Gravemeijer, K. (1997). Commentary Solving Word Problems: A Case of Modelling. Learning and Instruction, 7 (4) : 389-397.

Hardian, C. D. (2018). Etnomatematika, Analisis Pola dan Motif Batik Berdasarkan Wallpaper Group Serta Analisis Aktivitas Fundamental Matematis Menurut Bishop Pada Industri Batik di Desa Wijirejo, Kecamatan Pandak, Kabupaten Bantul, Daerah 
Istimewa Yogyakarta. Skripsi, Universitas Sanata Dharma, Yogyakarta.

Huda, N. T. (2018). Etnomatematika Pada Bentuk Jajanan Pasar di Daerah Istimewa Yogyakarta. Jurnal Nasional Pendidikan Matematika, 2 (2) : 217-232.

Huda, N. T. (2018). Kajian Aspek Geometris Fraktal Candi Prambanan dan Pengenalan Dimensi Fraktal Pada Siswa SMA. Tesis. Program Studi Pendidikan Matematika Program Magister, Universitas Sanata Dharma, Yogyakarta

Isnaini, L. (2019). Kerajinan Tenunan Anyaman Bali Terdapat Unsur Etnomatematika. Jurnal MathEducation Nusantara 2 (1) : 28-34.

Katsap, A. \& F. L. Silverman. (2016). Ethnomathematics of Negev Bedouins 'Existence in Forms, Symbols and Geometric Patterns. Rotterdam: Sense Publisher.

Krisnawati, Y. (2017). Kajian Etnomatematika terhadap tradisi pernikahan Yogyakarta oleh masyarakat di Kecamatan Minggir, Sleman, DIY, Dalam Rangka Penentuan AspekAspek Matematis yang dapat digunakan dalam pembelajaran matematika di SMP. Tesis. Program Studi Pendidikan Matematika Program Magister, Universitas Sanata Dharma

Lestari, I. (2015). Pengaruh Waktu Belajar dan Minat Belajar Terhadap Hasil Belajar Matematika. Jurnal Formatif, 3 (2) : 115-125.

Muhtadi, D., Sukirwan, Warsito, \& R. C. I. Prahmana. (2017). Sundanese Ethnomathematics: Mathematical Activities In Estimating, Measuring, and Making Patterns. Journal on Mathematics Education, 8 (2) : 185-198.

Maharani, A. \& S. Maulidia. (2018). Etnomatematika Dalam Rumah Adat Penjalin. Wacana Akademika, 2 (2) : 224-235.

Muslim, S. R. \& M. N. Prabawati.(2019). Eksplorasi etnomatematika dari para pengrajin payung geulis tasikmalaya jawa barat, Sesiomadika, 1270-1285.

Nurroh, S. (2017). Filsafat Ilmu Studi Kasus: Telaah Buku Filsafat Ilmu (Sebuah Pengantar Populer) oleh Jujun Suriasumantri. Tesis. Universitas Gadjah Mada, Yogyakarta.

Prabawati, M. N. (2016). Etnomatematika masyarakat pengrajin anyaman rajapolah kabupaten tasikmalaya, Jurnal Ilmiah Program Studi Matematika, 5 (1) : 25-31.

Pramudita, K. \& R. Rosnawati. (2019). Exploration of javanese culture ethnomatematics based on geometry perspective. Journal of Physics: Conference Series. 1200 : 1-8.

Rosa, M., \& Orey, D. C. (2011). Ethnomathematics : the cultural aspects of mathematics, 
Revista Latinoamericana de Etnomatematica, 4 (2) : 32-54.

Rosa, M., \& Orey, D. C. (2013). Ethnomodeling as a Research Theoretical Framework on Ethnomathematics and Mathematical Modeling. Journal of Urban Mathematics Education, 6 (2) : 62-80.

Rohayati, S., Karno, W. I. Chomariyah. (2017). Identifikasi Etnomatematika Pada Masjid Agung di Yogyakarta. Prosiding Seminar Nasional Pendidikann Matematika. 1-9.

Riswanto, D., Mappiare-at, A., \& Irtadji, M. (2016). Karakteristik Kepribadian Ideal Konselor (Studi Hermeneutika Gadamerian). Jurnal Pendidikan : Teori, Penelitian, dan Pengembangan. 1 (11) : 2113-2117.

Ridwan, H.. (2018). Etnomatematika: Tinjauan Aspek Geometris Tenun Suku Baduy di Desa Kanekes Kabupaten Lebak Provinsi Banten. Tesis. Universitas Pendidikan Indonesia, Bandung.

Sholeha, S. U. (2016). Studi Etnomatematika: Mengungkap Kearifan Lokal Budaya dan Matematika Pada Ritual Nutu Nganyaran Masyarakat Kasepuhan Ciptagelar Sukabumi. Skripsi. Universitas Pendidikan Indonesia, Bandung.

Sari, A. E. R. M. (2018). Aspek Matematis Pada Aktifitas Pembuatan Gerabah di Kasongan dan Implemenasinya Dalam Pembelajaran Matematika. Tesis. Universitas Sanata Dharma Yogyakarta.

Sudirman, A. L. Son, \& Rosyadi. (2018). Penggunaan etnomatematika pada batik paoman dalam pembelajaran geometri bidang di sekolah dasar. IndoMath : Indonesia Mathematics Education, 1 (1) : 27-34.

Sugiyono, (2008). Metode Penelitian Kuantitatif Kualitatif dan R\&D. Bandung Alfabeta

Taylor, P. (2016). Teaching Mathematics : Ethnomathematics, the Voice of Sociocultural Groups, 65 (3), 134-135.

Wahyuni, Astri. Dkk. (2013). Peran Etnomatematika Dalam membangun Karakter Bangsa.

Wilson, R. J., \& J. J Watkins. 1984. “Graf Pengantar”. Terjemahan oleh Theresia dan Tirta Seputro. 1992. Surabaya: University Press IKIP Surabaya.

Wihardi, D., R. G. Pratikto, \& S. Kristanty. (2015). Pergeseran makna motif batik yogykarta-surakarta. MAKNA 5 (2) : 105-13.

Yanti, D., \& Haji, S. (2019). Studi Tentang Konsep-Konsep Transformasi Geometri Pada Kain Besurek Bengkulu. JNPM : Jurnal Nasional Pendidikan Matematika, 3 (2) : 265- 


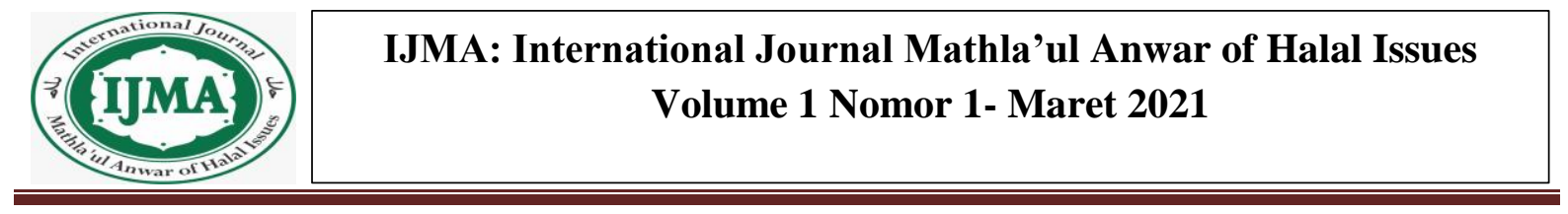

280.

Yulianto, E., S. Prabawanto, J. Sabandar, \& Wahyudin. (2019). Pola matematis dan sejarah batik sukapura: sebuah kajian semiotika, JP3M : Jurnal Penelitian Pendidikan dan Pengajaran Matematika, 4 (1): 15-30.

Zayyadi, M. (2017). Eksplorasi Etnomatematika Pada Batik Madura. Zigma, 2 (2) : 35-40.

Zulkifli, M. N. \& Dardiri.(2016). Etnomatematika Dalam Sistem Pembilangan Pada Masyarakat Melayu Riau. Kutubkhanah: Jurnal Penelitian Sosial Keagamaan, 19 (2) : $1-19$. 